\title{
Fertiliser drawn forward osmosis process: Pilot-scale desalination of mine impaired water for fertigation
}

Sherub Phuntsho ${ }^{\mathrm{a}}$, Jung Eun Kim ${ }^{\mathrm{a}}$, Mohammad AH Johir ${ }^{\mathrm{a}}$, Seungkwan Hong ${ }^{\mathrm{b}}$, Zhenyu Li ${ }^{\mathrm{c}, \mathrm{d}}$, Noreddine Ghaffour ${ }^{\mathrm{c}}$, TorOve Leiknes ${ }^{\mathrm{c}}$, Ho Kyong Shon ${ }^{\mathrm{a}}$

${ }^{a}$ Centre for Technology in Water and Wastewater, School of Civil and Environmental Engineering, University of Technology, Sydney (UTS), Broadway, NSW 2007, Australia

${ }^{b}$ School of Civil, Environmental \& Architectural Engineering, Korea University, 1, 5-ka, Anam-Dong, Sungbuk-Gu, Seoul 136-713, Republic of Korea

${ }^{c}$ King Abdullah University of Science and Technology (KAUST), Water Desalination and Reuse Center (WDRC), Biological and Environmental Sciences \& Engineering Division (BESE), Thuwal, 23955-6900, Saudi Arabia

${ }^{d}$ Belfer Center for Science and International Affairs, John F. Kennedy School of Government, Harvard University, Cambridge, MA 02138 USA

* Corresponding author. Email: Hokyong.Shon-1@uts.edu.au

\section{Abstract}

The pilot-scale fertiliser driven forward osmosis (FDFO) and nanofiltration (NF) system was operated in the field for about six months for the desalination of saline groundwater from the coal mining activities. Long-term operation of the FDFO-NF system indicates that simple hydraulic cleaning could effectively restore the water flux with minimal chemical cleaning frequency. No fouling/scaling issues were encountered with the NF post-treatment process. The study indicates that, FDFO-NF desalination system can produce water quality that meets fertigation standard. This study also however shows that, the diffusion of solutes (both feed and draw) through the cellulose triacetate (CTA) FO membrane could be one of the major issues. The FO feed brine failed to meet the effluent discharge standard for $\mathrm{NH}_{4}{ }^{+}$and $\mathrm{SO}_{4}{ }^{2+}$ (reverse diffusion) and their concentrations are expected to further increase at higher feed recovery rates. Low rejection of feed salts $\left(\mathrm{Na}^{+}, \mathrm{Cl}^{-}\right)$by $\mathrm{FO}$ membrane may result in their gradual build-up in the fertiliser draw solution (DS) in a closed FDFO-NF system eventually affecting the final water quality unless it is balanced by adequate bleeding from the system through NF and re-reverse diffusion towards the FO feed brine. Therefore, FO membrane 
with higher reverse flux selectivity than the CTA-FO membrane used in this study is necessary for the application of the FDFO desalination process.

Key words: Forward osmosis (FO), pilot-scale operation, desalination, fertigation, irrigation

\section{Background}

Water stress is increasingly felt all over the world $[\underline{1}, \underline{2}]$ and the impact of climate change is expected to further worsen the fresh water scarcity issues $[\underline{3}, \underline{4}]$. Effective water management strategies to alleviate this include supplementing existing water resources using impaired water such as through wastewater recycling and reuse, and desalination [ $\underline{5}, \underline{6}]$. Nowadays, about $63 \%$ of the established desalination plant capacity around the world is based on using membrane technology, mainly using reverse osmosis (RO) process [7]. Despite significant progress in the technologies, desalination still remains a capital and energy intensive process making the technology affordable only to few privileged societies in the world []. Desalination has a high carbon footprint and also remains uneconomical for irrigation where a large amount of water is required. Irrigation alone constitutes about $70 \%$ of world's total water consumption $[\underline{8}, \underline{9}]$ and water scarcity could have a devastating impact on agriculture production and food security as the limited fresh water resources are prioritised for other uses. Therefore, more cost-effective desalination technologies are needed to make irrigation affordable to meet the increasing food demand for the world's growing population and the world's increasing affluent society.

New and emerging technologies are being investigated, and forward osmosis (FO) process has emerged as one of the most promising candidates for low-pressure, low-energy and lowcost desalination [10-13]. FO is an innovative membrane-based process that uses concentration difference between the two solutions as the main driving force to separate 
water from the saline water sources instead of hydraulic pressure as in the RO process. However the energy consumption depends on the types of draw solute used and its end use applications. When a highly concentrated draw solution (DS) and a saline feed solution (FS) are separated by a special osmotic or FO membrane, the water moves from the lower concentrated FS towards the higher concentrated DS by natural osmosis due to osmotic pressure difference without the need of an external energy source. The DS finally becomes diluted but it cannot be used directly for potable purpose. Finding suitable draw solutes that can be easily separated from the diluted DS is therefore still a big challenge for potable water applications $[\underline{10-12}, \underline{14}]$.

The concept of fertiliser driven FO (FDFO) desalination, in which saltwater is converted into nutrient rich water for irrigation using a fertiliser solution as DS and this FO process intends to avoid the issue of DS separation and recovery system [15-17]. Fertiliser is needed for the growth of crops/plants and the diluted fertiliser DS can thus be directly used for irrigation (referred to as fertigation) $[\underline{15}, \underline{16}]$. The diluted fertiliser concentration must meet the nutrition standards for direct fertigation and this has however been found challenging. The final fertiliser concentrations of the diluted DS are limited by the total dissolved solid (TDS) or osmotic pressure of the feed water based on the principle of osmotic equilibrium between the DS and the FS [18]. Some of the options to reduce fertiliser concentrations include direct dilution by mixing with the existing fresh water sources or other treated impaired water sources, using blended fertiliser DS to reduce the concentration of individual nutrients [19] and using nanofiltration (NF) as post-treatment process to remove the excess fertiliser concentrations [20]. Lately, pressure assisted osmosis (PAO) has also been investigated as an innovative and more practical way of reducing the fertiliser concentration without NF as a separate post-treatment process $[\underline{21}, \underline{22}]$. 
The FDFO process has so far mostly studied through lab-scale experiments except for a recent process optimisation study using 8040 FO membrane module [23, 24]. This paper reports a six-month field study of the FDFO-NF process at a pilot-scale level for the desalination of saline water produced during coal mining activities at one of the coal mining sites in New South Wales, Australia.

\section{Materials and Methods}

\subsection{Location and source of saline water}

The FDFO-NF pilot desalination system was operated at Newstan Colliery (Centennial Coal Pty. Ltd), State of New South Wales (NSW), Australia (Figure 1). The saline water used for the pilot-scale FDFO-NF study was obtained directly from a newly built water treatment plant (WTP of $15 \mathrm{ML}$ day capacity), which treats mine impaired groundwater. The WTP process consists of a screen mesh, coagulation/flocculation process followed by a lamella clarifier and multi-media filter, before finally being discharged to the LT Creek.

Typical characteristic of the treated coalmine water from the WTP are presented in Table 1. Water samples from the WTP were collected at the start (12 samples for all short and longterm experiments) and end (six samples for only long-term experiments) of each test operational cycle. The composition of the water samples analysed as per the APHA standards [25] are presented in Table 1 . The TDS of the saline groundwater was $1,277( \pm 45) \mathrm{mg} / \mathrm{L}$ with electrical conductivity (EC) of $2.37( \pm 0.07) \mathrm{mS} / \mathrm{cm}$. This is acceptable for irrigation water as much higher salinity has been used for some plants, e.g. strawberry tree $(3-4 \mathrm{mS} / \mathrm{cm})$, cherry plum $(4-8 \mathrm{mS} / \mathrm{cm})$ and brush cherry $(>8 \mathrm{mS} / \mathrm{cm})$ [26]. Although already at a lower feed salinity, the FDFO operation is able to produce a diluted DS with lower fertiliser concentrations, however, using a low salinity feed water does not justify using two different processes (i.e. FDFO and NF) and hence the pilot-scale FDFO-NF system was tested in the 
field with a higher or enhanced salinity. The normal saline water from the WTP was therefore first concentrated using a FO process with $1.5 \mathrm{M} \mathrm{MgSO}_{4}$ as DS at about $50 \%$ total recovery rate to raise the saline feed water to about EC 5.4( \pm 0.5$) \mathrm{mS} / \mathrm{cm}$ or TDS $2,491( \pm 85) \mathrm{mg} / \mathrm{L})$ for subsequent pilot testing. The characteristics of the concentrated feed water used for the FDFO process is presented in Table 1 along with the normal saline water from the WTP.

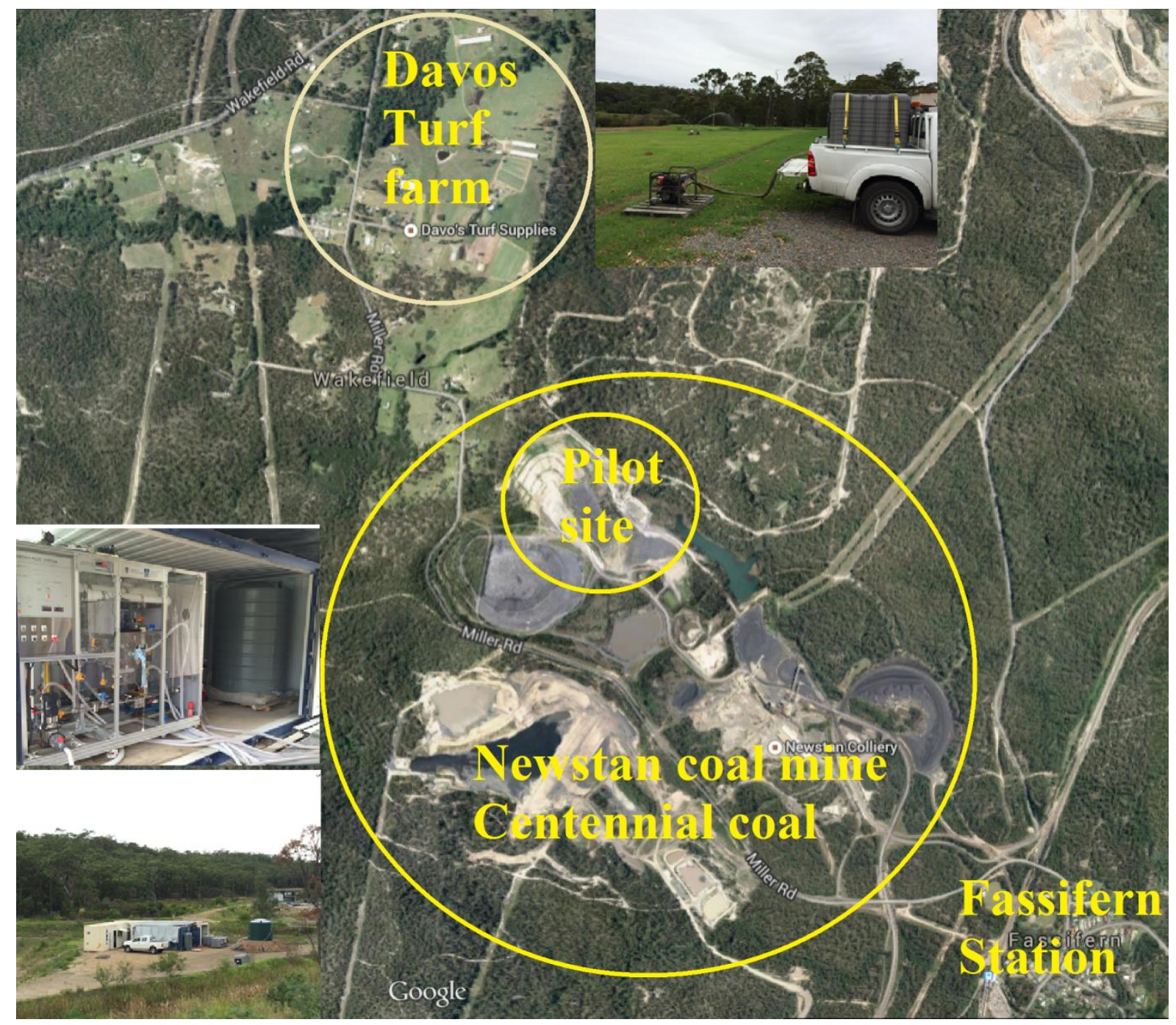

Figure 1: Location of the pilot-scale FDFO-NF desalination testing site at the Centennial Coalmine site under the State of NSW, Australia. 
Table 1: Characteristics of the saline water from a water treatment plant for the $1^{\text {st }}$ long term operation cycle shown a typical sample. (the data in the bracket refers to the standard deviation of twelve collected samples presented in the brackets).

\begin{tabular}{|c|c|c|}
\hline Composition & $\begin{array}{c}\text { Normal saline water } \\
\text { from the WTP }\end{array}$ & $\begin{array}{l}\text { Feed water used for the } \\
\text { FDFO operations }\end{array}$ \\
\hline $\mathrm{pH}$ & $7.50( \pm 0.26)$ & $7.8( \pm 0.30)$ \\
\hline $\mathrm{EC}(\mathrm{mS} / \mathrm{cm})$ & $2.37( \pm 0.07)$ & $5.4( \pm 0.50)$ \\
\hline TDS (mg/L) & $1,277( \pm 45)$ & $2,491( \pm 85)$ \\
\hline Dissolved organic carbon & $1.2( \pm 0.2)$ & $2.1( \pm 0.53)$ \\
\hline Turbidity (NTU) & $0.85( \pm 0.15)$ & $1.0( \pm 0.15)$ \\
\hline Orthophosphate (mg/L P) & $<0.006$ & $<0.009$ \\
\hline Nitrate (mg/L N) & $<0.005$ & $<0.005$ \\
\hline Nitrite (mg/L N) & N/D & N/D \\
\hline Ammonia (mg/L N) & $12.3( \pm 1.7)$ & $12.0( \pm 4.0)$ \\
\hline Sodium (mg/L) & $470( \pm 18.4)$ & $812( \pm 67)$ \\
\hline Potassium (mg/L) & $4.0( \pm 0.3)$ & $7.0( \pm 1.1)$ \\
\hline Calcium (mg/L) & $30.1( \pm 1.9)$ & $48.0( \pm 3.8)$ \\
\hline Magnesium (mg/L) & $9.0( \pm 0.82)$ & $22.0( \pm 2.1)$ \\
\hline SAR & $19.5( \pm 4.0)$ & $24.5( \pm 3.4)$ \\
\hline Chloride (mg/L) & $510( \pm 154)$ & $983( \pm 26)$ \\
\hline Sulphate $\left(\mathrm{mg} / \mathrm{L} \mathrm{SO}_{4}{ }^{2-}\right)$ & $241( \pm 42)$ & $607( \pm 27)$ \\
\hline Aluminium (mg/L) & $<0.2$ & 0.023 \\
\hline Arsenic (mg/L) & $<0.002$ & 0.001 \\
\hline Cadmium (mg/L) & $<0.001$ & 0.000 \\
\hline Chromium (mg/L) & 0.002 & 0.000 \\
\hline Copper (mg/L) & 0.001 & 0.043 \\
\hline Iron $(\mathrm{mg} / \mathrm{L})$ & 0.069 & 0.014 \\
\hline Manganese (mg/L) & 0.002 & 0.010 \\
\hline Nickel (mg/L) & 0.008 & 0.022 \\
\hline Lead (mg/L) & $<0.001$ & 0.001 \\
\hline Zinc (mg/L) & 0.035 & 0.189 \\
\hline
\end{tabular}

\subsection{Fertiliser draw solution}

In this pilot-scale study, sulphate of ammonia (SOA) or $\left(\mathrm{NH}_{4}\right)_{2} \mathrm{SO}_{4}$ was selected as the fertiliser DS for two main reasons. Firstly, SOA being a divalent compound, its rejection by the NF membrane is much higher than a monovalent DS [20] while its performances under the FO process is comparable with other DS based on previous studies [15, $\underline{19]}$. 
The fertiliser DS was prepared by dissolving a technical grade $\left(\mathrm{NH}_{4}\right)_{2} \mathrm{SO}_{4}$ (supplied in $25 \mathrm{~kg}$ bag from Chem-Supply, Australia) in tap water at ambient temperature using a variable speed mixer until all the salts were completely dissolved. The SOA solution appeared slightly murky in colour indicating the presence of impurities. In order to prevent membrane fouling on the support layer side of the FO membrane, the concentrated DS was first pre-filtered using a microfiltration (MF of $0.45 \mu \mathrm{m}$ pore size) before use. Four different SOA DS concentrations were used in this study: $0.5 \mathrm{M}$ for baseline flux and $0.95 \mathrm{M}, 1.89 \mathrm{M}$ and 2.84 $\mathrm{M}$ for FDFO performance testing. All long term FDFO operations were conducted using a SOA DS concentration of 1.89 M (i.e. 2 bags SOA for 200 L DS). The resulting osmotic pressure as a function of SOA concentration are presented elsewhere [15, 16]. The SOA generates osmotic pressure of $23.6,43.9,87.0$ and 131.5 atm at $0.5 \mathrm{M}, 0.95 \mathrm{M}, 1.89 \mathrm{M}$ and 2.84 M, respectively calculated using the thermodynamic modelling software OLI Stream Analyser (Version 9.1 OLI System Inc. Morris Plains, NJ).

\subsection{Operation of pilot-scale FDFO-NF desalination system}

A schematic layout of the pilot-scale FDFO-NF system is presented in Figure 2. The pilot system was made up of the FO process containing two numbers of spiral wound 8040 cellulose triacetate (CTA) FO membrane modules (each module containing 1 element) connected in parallel with a total membrane area of $20.2 \mathrm{~m}^{2}$ (Hydration Technology Innovations, Albany, OR). The intrinsic properties of the CTA FO membrane used in this study are widely reported and based on our earlier study, the pure water permeability of the CTA FO membrane was observed to be $1.02 \mathrm{Lm}^{-2} \mathrm{~h}^{-1} \mathrm{bar}^{-1}$ and salt rejection of $93 \%(5 \mathrm{~g} / \mathrm{L}$ $\mathrm{NaCl}$ [27]. The NF process consisted of one 4040 spiral wound polyamide thin film composite (TFC) NF membrane module with a membrane area of $7.9 \mathrm{~m}^{2}$ (NE90 CSM membranes, Woongjin Chemicals, now Toray Chemicals, Korea). According to our earlier 
study, the 4040 NE90 membrane used in this study had a pure water permeability coefficient of $3.82 \mathrm{Lm}^{-2} \mathrm{~h}^{-1}$ bar $^{-1}$ and salt rejection of $97 \%(2 \mathrm{~g} / \mathrm{L} \mathrm{NaCl})$ [28]. The system was not fully optimised in terms of its capacity, consequently each process had to be operated as a batch process and not as a continuous process. Both the diluted DS and feed concentrate from their respective outlets were therefore recycled back to their respective tanks during the batch operation mode. The volumes of the DS in the DS tank therefore gradually increased while its concentration, and hence the driving force, gradually decreased with operation time during each batch cycle. The feed concentrate from the FO module outlet was also recycled back to the FS tank. The volume of the FS tank, however was maintained the same $(5,000 \mathrm{~L})$ by filling the FS tank with incoming normal saline water from the WTP using a float valve installed at the inlet of the FS tank. In this way, the concentration of the FS also increased slightly with operation time. The long-term batch operation of the FDFO process continued on till the DS tank $(5,000 \mathrm{~L})$ was full with the diluted DS, taking about 7 days. During the process optimisation study, however, each batch of the FDFO process was operated for only about 6 hours duration.

The final diluted fertiliser DS, after the FDFO batch process, was then processed by the NF membrane, (operated in the batch mode) at a constant operating pressure of 25 bar. The reject/concentrate from the NF was recycled back to the NF feed tank while the NF permeate was stored in a separate tanks. In this mode of operation, the fertiliser solution in the NF feed tank (earlier diluted DS tank) increased with the NF operation time.

Flow meters, pressure gauges and electrical conductivity (EC) meters were installed at both the inlet and outlet points of the FDFO and NF processes, with all devices connected to a PC for online data acquisition. EC was used as a surrogate for the FS or DS concentrations at the module inlet/outlet points. The pilot system was not built with a full SCADA system for 
remote monitoring and control, however, the FO process was operated continuously for several days with visual monitoring conducted through live video feed while the NF was operated during the daytime only. The water flux for the FDFO process was calculated based on the flow meter reading between the DS outlet and inlet while for the NF process, the flux for the NF process was obtained directly from the NF permeate flow meter readings. All the pilot plant operations were conducted at ambient temperature, without any external control on the environment, between March and August 2014. The ambient air temperature varied considerably with the average daily minimum and maximum temperatures of $15.8^{\circ} \mathrm{C}$ and $26.5^{\circ} \mathrm{C}$ (March), $13.0^{\circ} \mathrm{C}$ and $24.0^{\circ} \mathrm{C}$ (April), $9.0^{\circ} \mathrm{C}$ and $22.6^{\circ} \mathrm{C}$ (May), $7.7^{\circ} \mathrm{C}$ and $19.5^{\circ} \mathrm{C}$ (June), $4.2^{\circ} \mathrm{C}$ and $18.8^{\circ} \mathrm{C}$ (July) and $6.1^{\circ} \mathrm{C}$ and $18.3^{\circ} \mathrm{C}$ (August), respectively, [29]. The temperatures of the DS and FS in their respective tanks however remained fairly constant at around 23 to $24^{\circ} \mathrm{C}$. This is probably due to heating from the pumps. A fresh SOA DS was used for each operational cycle.

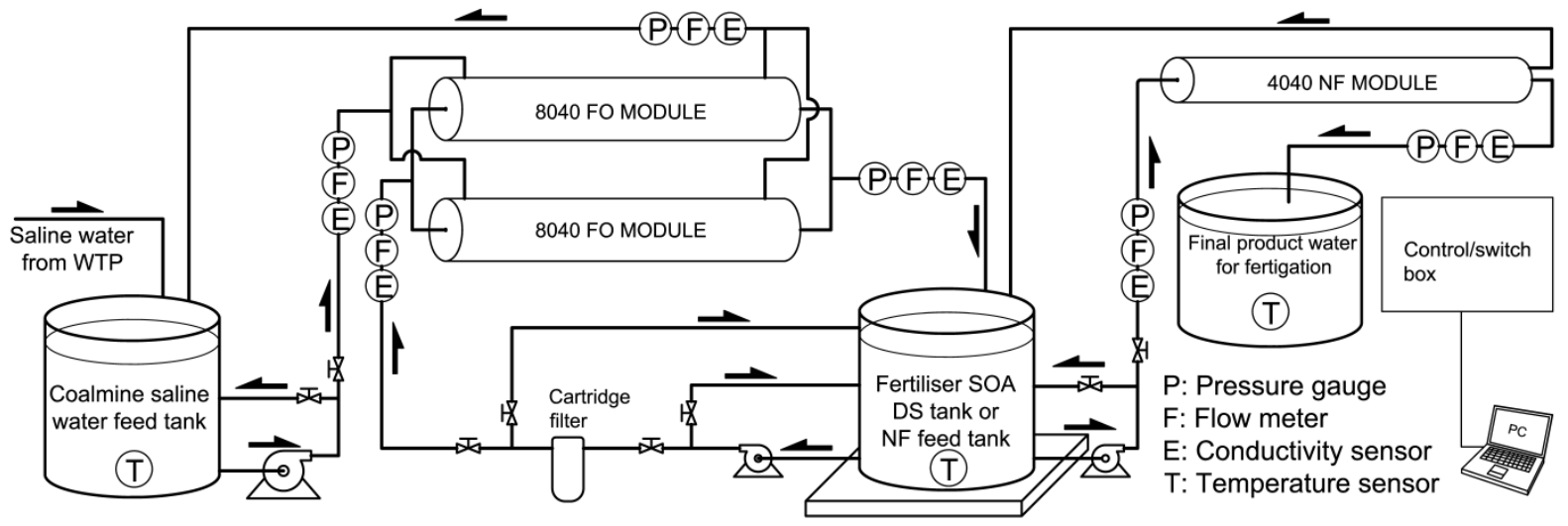

Figure 2: Schematic diagram of the FDFO-NF desalination system used for pilot-scale testing in the field.

\subsection{Water quality monitoring and the test fertigation}


Water quality was analysed according to the APHA standards [25]. A Perkin Elmer Elan DRC-e Inductively Coupled Plasma Mass Spectrometer was used for element analysis, similar to our earlier studies $[\underline{20}, \underline{27}]$. Water quality was also assessed in terms of sodium absorption ratio (SAR) values, measuring the relative concentrations of $\mathrm{Na}^{+}$to $\mathrm{Ca}^{2+}$ and $\mathrm{Mg}^{2+}$ ions in the water [26]. The calculation of SAR values are described elsewhere [26, $\underline{30]}$. Irrigation water with high SAR values is known to cause sodicity (or sodium toxicity) and loss of soil structure thereby contributing to soil degrading and poor yield of the crops [26].

\section{Results and discussion}

\subsection{Process optimisation study}

For the FDFO process optimisation, only two major operating parameters were considered: initial DS concentrations and the feed flow rates. Data in Figure 3 show the variations of the water flux, cumulative volume of water extracted $(\Sigma \mathrm{V})$, DS and FS conductivity with operation time during (i.e. batch mode operation where both the DS and FS were recycled back to their respective tanks). The gradual decrease in the water flux with operation time (shown in Figure 3(a)) is because of the increase in the cumulative volume of the water extracted $(\Sigma \mathrm{V})$ which in turn dilutes the DS in the DS tank thereby gradually losing the driving force with time. The initial water fluxes with $0.95 \mathrm{M}, 1.89 \mathrm{M}$ and 2.84 M SOA DS concentrations were 5.9, 7.5 and $8.8 \mathrm{Lm}^{-2} \mathrm{~h}^{-1}$, respectively. These water fluxes are slightly non-linear with the DS concentrations consistent with many previous lab-scale studies because of the enhanced dilutive internal concentration polarisation (ICP) effects when operated at higher water fluxes $[\underline{24}, \underline{27}, \underline{31}, \underline{32}]$.

Figure 3(b) shows the EC variations of the DS at the inlet and the outlet of the FO module with operating time. The DS concentration difference (driving force) between the inlet and outlet is much higher at the beginning, indicating the higher DS dilution factor (i.e. ratio of 
DS concentrations at the inlet to the outlet) achieved within the module during the initial stages of operation. However, the DS dilution factor at the module outlet decreases gradually with operation time due to cumulative loss of the driving force (cumulative DS dilution in the batch process) and hence the water flux with time. Although the DS dilution factor at the module outlet increases at higher inlet DS concentration, this corresponds to higher diluted DS concentration level at the outlet, as evident from the EC of the diluted DS between 1.89 $\mathrm{M}$ and 2.85 M. This indicates that when higher DS concentrations are used, it may require more membrane area (or membrane elements) in series to reach the desirable DS dilution (up to osmotic equilibrium concentration) within a single stage FO process [18].

Figure 3(c) shows the variations of the FS EC at the inlet/outlet and the feed recovery rates with operation time for the FO module. The feed recovery rates of a single 8040 FO module were $4.2 \%$ at $2.84 \mathrm{M}$ SOA DS concentration, reducing to $2.6 \%$ at $0.95 \mathrm{M}$ SOA DS concentration. The feed recovery rate also decreased with time due to the loss of driving force and hence the water flux. The feed recovery rates are comparatively lower than the rated feed recovery rates of a single $8040 \mathrm{RO}$ element (BW30-440i, membrane area of $41 \mathrm{~m}^{2}$, recovery rates of $15 \%$ at applied pressure of 15 bar) using a feed water of $2000 \mathrm{mg} / \mathrm{L} \mathrm{NaCl}$ [33]. Feed recovery rates for the FO module could be increased by using higher initial DS concentration (driving force), however, this also results in higher concentration level of the diluted DS that comes out of the module (ref Figure 3.b) as discussed earlier, which is not desirable. Several factors might contribute towards the lower feed recovery rates of the CTA 8040 FO element. One of the reasons could be due to the comparatively higher cross flow rate differences between the FS $\left(6.0 \mathrm{~m}^{3} \mathrm{~h}^{-1}\right)$ and FS $\left(0.6 \mathrm{~m}^{3} \mathrm{~h}^{-1}\right)$ as recommended by the manufacturer for the module operation to maintain a suitable pressure differential between the inlet and out of the module. The other reason could be due to the low packing density of the CTA 8040 FO element $\left(10.1 \mathrm{~m}^{2}\right)$ compared to $\mathrm{RO}$ membranes of similar size $\left(41 \mathrm{~m}^{2}\right.$, Filmtec DOW ${ }^{\mathrm{TM}}$ 
Chemicals) and lower permeability, and hence lower water flux of the CTA FO membrane compared to TFC RO membrane.

The influence of feed flow rates on the performance of the FDFO process is presented in Figure 3(d) at different flow rates of 3.0, 4.2 and $6.0 \mathrm{~m}^{3} \mathrm{~h}^{-1}$. It is evident from these results that, no significant increase in the water flux was observed when the FDFO pilot-scale unit was operated at higher feed flow rates. This is possibly due to the very low feed recovery rates $(2.6-4.2 \%)$ at which the FO modules were operated and hence the differences in the fluxes are not noticeable. Therefore, all the subsequent long-term experiments were conducted at a feed flow rate of $4.2 \mathrm{~m}^{3} \mathrm{~h}^{-1}$ as it provided a reasonable pressure differential between the different inlets and outlets of the module, as recommended by the manufacturer.

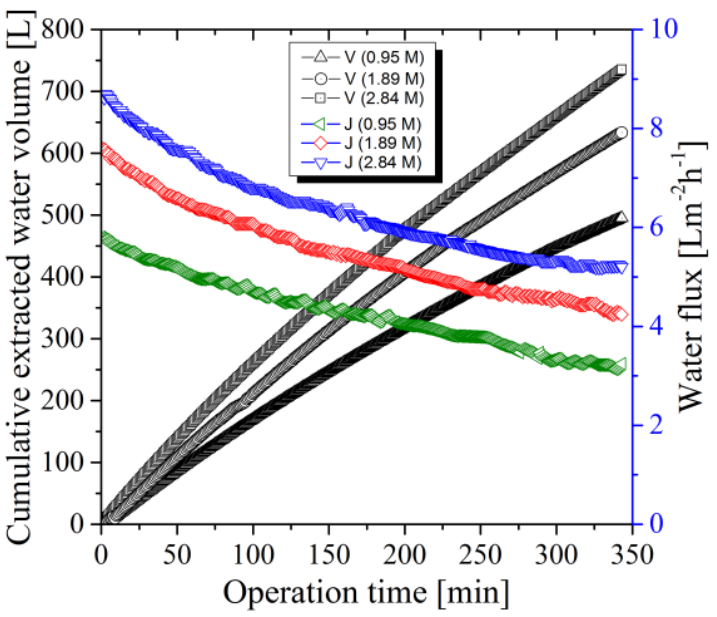

(a)

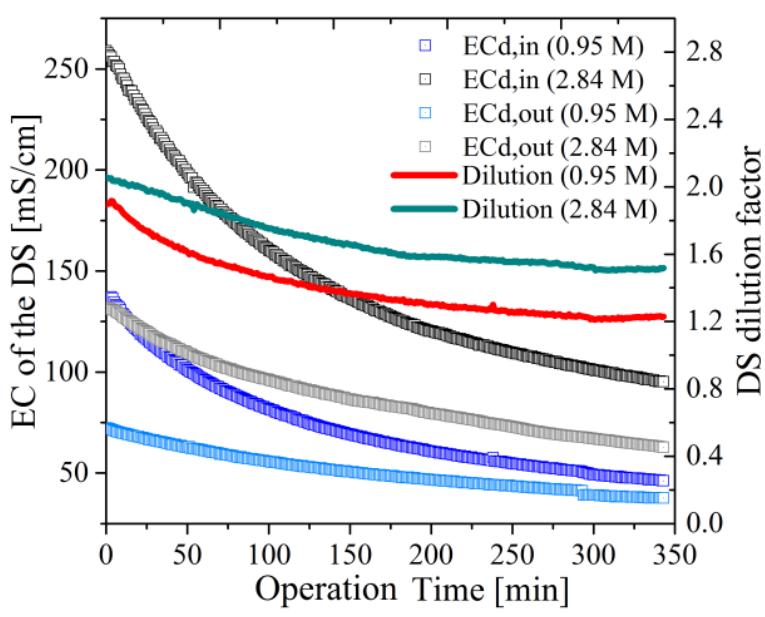

(b) 


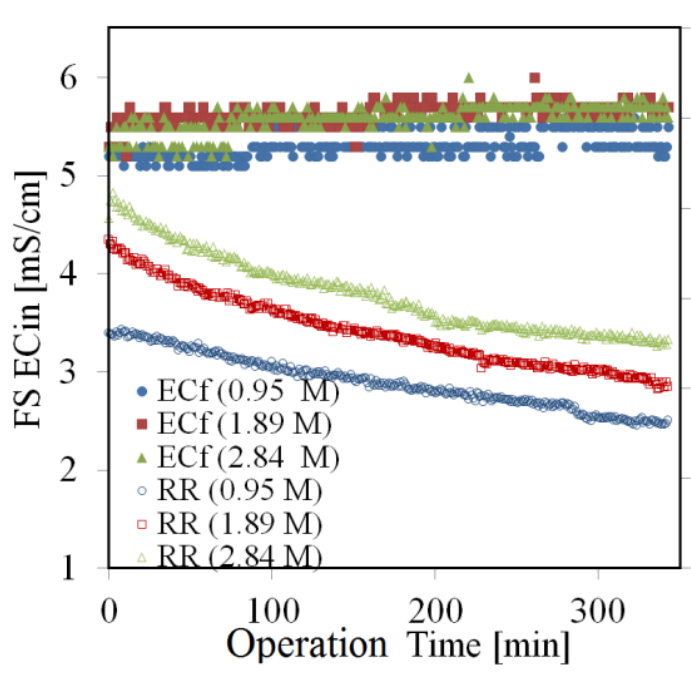

(c)

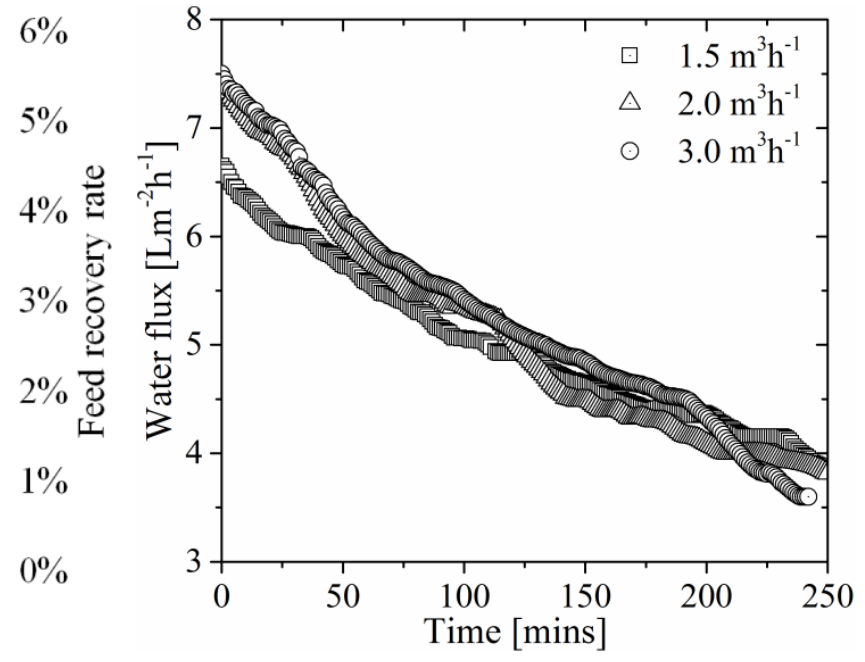

(d)

Figure 3: Variations of the performance parameters during the FDFO pilot unit process optimisation process. (a) Cumulative volume of water extracted and the water flux with time, (b) DS concentrations or EC at the inlet/outlet and the dilution factor with time, (c) feed TDS or EC and feed recovery rates with time and (d) water flux under different feed flow rates. Initial DS and FS volumes are $200 \mathrm{~L}$ and 5,000 L respectively.

\subsection{Long-term operation of the FDFO process}

Based on the results in Figure 3, 1.89 $\mathrm{M}$ was selected for all the subsequent long-term operation of the pilot-plant system. Each batch of long-term FDFO operation initially started with $200 \mathrm{~L}$ of $1.89 \mathrm{M} \mathrm{SOA}$ as DS and at a constant volume $(5000 \mathrm{~L})$ of saline feed water. At the end when the DS tank was full to 5,000 L, its final SOA DS concentration reached to around $0.075 \mathrm{M}(4.0 \mathrm{~atm})$, which is closer to the final FS TDS of 4,000 mg/L (3.0 atm). The minimum initial DS volume of 200 L was necessary to accommodate the DS within the dead volume of the pipes, fittings and pump. For the long-term performance, the pilot-scale FDFO process was operated for a total of six cycles under a batch mode until the 5,000 L DS tank was fully filled, results presented in Figure 4. 
The variations in water flux with operation time appear quite similar for all the six cycles, indicating a consistent performance of the FDFO process under each batch trial. A closer observation between each batch cycle in Figure 4(a), however, shows that the water flux in the fourth cycle is significantly lower than water fluxes in the other cycles (i.e. the sharper flux decline). Figure 4(b) presents the water flux as a function of cumulative volume, representing water flux under similar DS concentrations (driving force) with the change of the cumulative volume. The baseline water flux presented as a subset plot within Figure 4(b) and conducted using 0.5 M SOA as DS and tap water as FS immediately after Cycle 4 (before cleaning) is much lower than the original baseline water flux, indicating that the CTA FO membrane was indeed fouled during the $4^{\text {th }}$ cycle of operation. The reduction in the water flux observed in the $4^{\text {th }}$ cycle was unexpected since the feed water used for the FDFO process had similar turbidity of around 1.3 NTU (data not presented). However, it was observed that the turbidity of the feed water in the feed tank at the end of the $4^{\text {th }}$ cycle had significantly increased from the initial 1.3 NTU to 6.5 NTU (data not presented). On investigation, it was observed that algae had grown inside the feed tank, which is assumed to have been the main contributing factor for this sharp flux decline. The continuous recycling of feed water along with the reverse diffusion of ammonia nitrogen towards the feed tank from the SOA DS is assumed to have enhanced algal growth in the feed tank. Opening of the tank and exposure to the sun might also have promoted algae to grow in the tank. Algal growth is evident from the pictures of the water samples taken out from the tank, shown within Figure 4(b). Since there was no cartridge pre-filter between the feed water tank and the FO membrane module, the algae particles could have contributed to the FO membrane flux decline. Although algae presence was evident in this cycle, flux decline due to biofouling cannot be ruled out entirely as the FDFO process had run for about 4 cycles without any cleaning. It is also therefore 
possible that biofouling may partly contributed towards the flux decline given the presence of dissolved organic matter in the FDFO feed of about 2.1( \pm 0.53$) \mathrm{mg} / \mathrm{L}$ (refer Table 1).

Before the subsequent cycles of FDFO operations, the FO membranes were subjected to hydraulic cleaning using clean tap water at feed flow rates of $6.0 \mathrm{~m}^{3} \mathrm{~h}^{-1}$ for about 60 minutes and the baseline flux was then determined again. The baseline fluxes presented within Figure 4(b) indicate that hydraulic cleaning was almost able to fully recover the water flux and hence no chemical cleaning was required before the next cycle of operation. Even at the end of the $6^{\text {th }}$ cycle, the water flux and also the baseline flux was still comparable to the earlier cycles, indicating that the FO membrane performed quite well without any significant fouling or scaling issues during the long-term operations. For the subsequent batches (cycles 5 and 6), the feed water in the tank containing algae was filtered by MF before the next cycle of long-term operation. In order to prevent the regrowth of algae in the feed tank, the feed tank was completely closed and housed inside the shed.

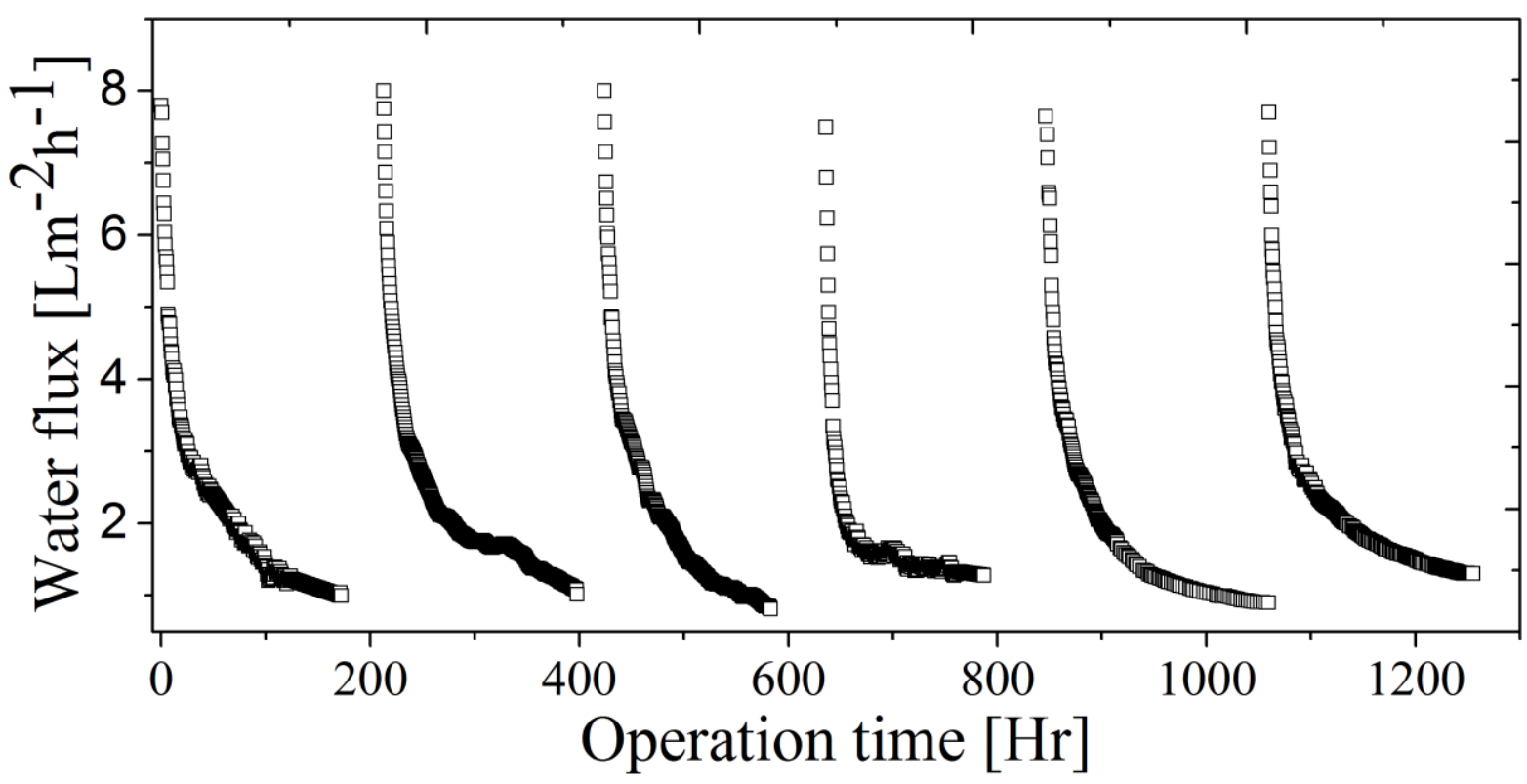

(a) 


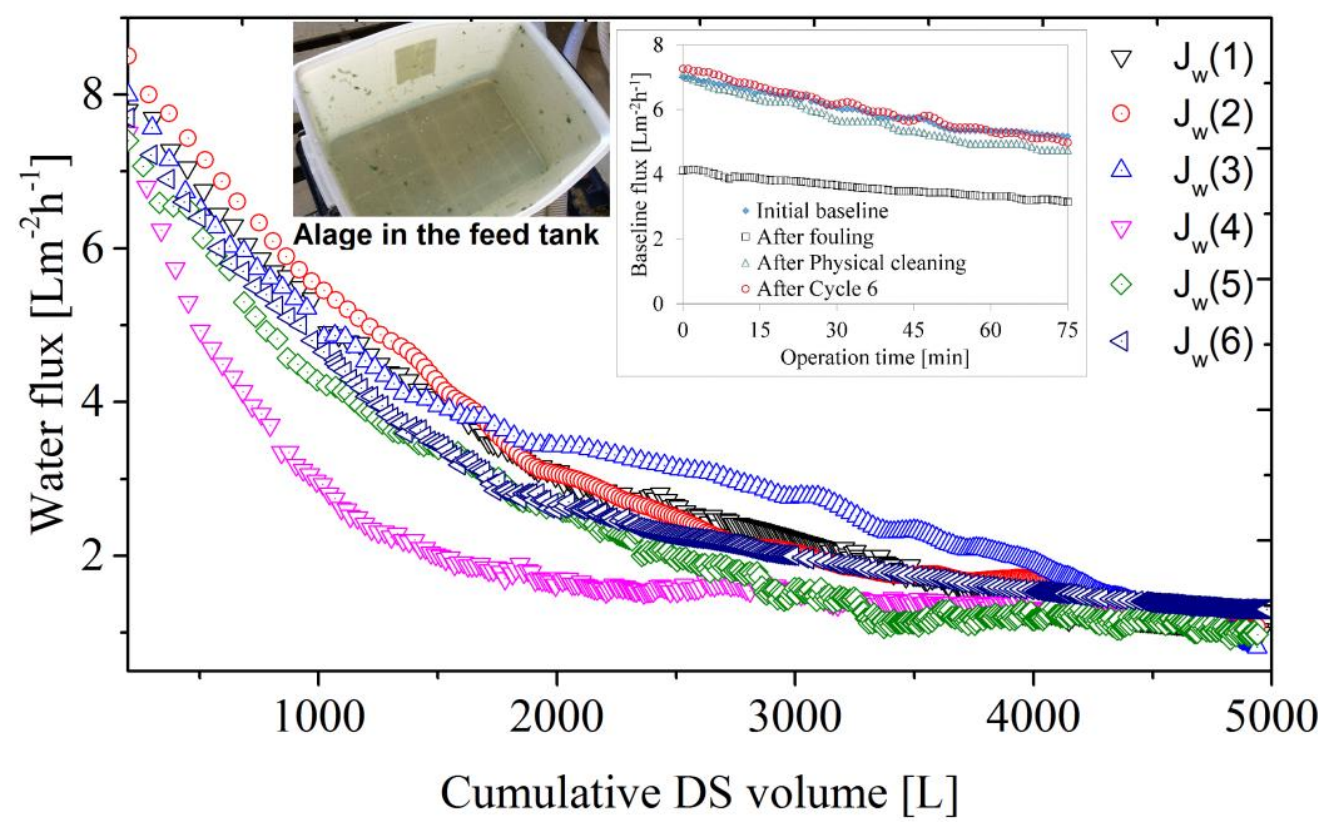

(b)

Figure 4: Performance of the FDFO desalination process on longer run cycles. (a) Variation of water flux with operation time and (b) the variation of water flux with the cumulative volume of water extracted during the batch operation process showing together the baseline fluxes before and after cleaning of the FO membrane and the picture showing algae growth in the feed water tank during the cycle 4 of the operation. Baseline fluxes were conducted using $0.5 \mathrm{M}$ SOA as DS and tap water as FS at a feed crossflow rate of $4.2 \mathrm{~m}^{3} \mathrm{~h}^{-1}$.

Table 2 shows the typical composition of the final diluted SOA fertiliser DS (cycle 1) along with their respective initial and final FS compositions. The final diluted fertiliser DS with an EC of $13.49( \pm 1.5) \mathrm{mS} / \mathrm{cm}$ or a TDS of $7,604( \pm 845) \mathrm{mg} / \mathrm{L}$ and $\mathrm{NH}_{4}{ }^{+}$of $1,897( \pm 143) \mathrm{mg} / \mathrm{L}$ is too high for direct fertigation to the plants [34]. Fertigation with high salinity water could decrease the biomass production of the plants due to lowering of plant water potentials and also cause specific ion toxicities and ion imbalances [35]. Assuming a TN of $200 \mathrm{mg} / \mathrm{L}[\underline{16}$, $\underline{19}, \underline{34}$ for certain plants as the maximum concentration limit, this diluted fertiliser DS would require additional dilution by a factor of about 10 which is a significant volume of additional fertigation water required. The excess fertiliser draw solutes would therefore require reducton 
or dilution before use and the NF process was therefore used as post-treatment for further reducing (or diluting) the fertiliser concentration.

The osmotic pressure of the final diluted fertiliser DS (estimated using ROSA) was $3.7( \pm 0.41)$ bar against the initial feed osmotic pressure of 1.52(0.05) bar. The osmotic pressure of the final diluted DS is expected to be higher than the initial feed osmotic pressure used in this study since the FDFO process was operated in a batch mode in which the TDS or the osmotic pressure of the feed continued to increase with time from 1.52( \pm 0.05$)$ bar (initially) to $2.85( \pm 0.14)$ bar by the end of each batch operation. The osmotic pressure of the final diluted DS is still higher than the osmotic pressure of the final FS, indicating that the diluted DS concentration has not yet reached osmotic equilibrium with the feed osmotic pressure, and hence further dilution could have been possible if the FDFO process had been operated further. This osmotic pressure of the final diluted DS is $10-30 \%$ higher than the osmotic pressure of the final feed concentrate.

From Table 2, it is clear that the CTA FO membrane used in this study led to significant transfer of ions across the membrane in both directions. Rejection of the individual feed ions were observed to be only between 80 and $98 \%$, except for $\mathrm{Na}$ at $72 \%$, indicating that the rest of the feed ions have diffused through the membrane towards the DS. This low rejection of the CTA FO membrane, especially monovalent ions such as $\mathrm{Na}^{+}$and $\mathrm{Cl}^{-}$, could be a cause of concern, as these unwanted feed solutes are expected to eventually accumulate in the DS during the NF post-treatment process after repetitive cycles of recycling and reuse operations. A detailed discussion on this implication is included later under Section 3.4.

Table 2 also presents the specific reverse solute flux (SRSF) of the SOA DS in terms of $\mathrm{NH}_{4}^{+}$ and $\mathrm{SO}_{4}{ }^{2-}$ concentrations. Although the term reverse solute flux or RSF (in $\mathrm{gm}^{-2} \mathrm{~h}^{-1}$ ) is also commonly used to measure the rate of reverse diffusion [36-38] of draw solutes in this study, 
SRSF has been used as this parameter relates to the quantitative measurement of the reverse diffusion of draw solutes towards the FS per unit volume of water extracted in the FO process $[27, \underline{39}, \underline{40]}$. The RSF increases with the increase in the DS concentration, however, it has been observed that the SRSF (or the ratio of $\operatorname{RSF}\left(\mathrm{gm}^{-2} \mathrm{~h}^{-1}\right)$ to the water flux $\left(\mathrm{Lm}^{-2} \mathrm{~h}^{-1}\right)$ ) is fairly constant for a particular draw solute [40] and hence SRSF is used as one of the performance parameters in this study instead of RSF. The SRSF of the SOA DS were 105( \pm 76$) \mathrm{mg} / \mathrm{L}$ for $\mathrm{NH}_{4}{ }^{+}$and $401( \pm 85) \mathrm{mg} / \mathrm{L}$ for $\mathrm{SO}_{4}{ }^{2-}$ as shown in Table 2. These SRSF values are slightly lower than the SRSF usually observed during lab-scale experiments in our earlier study [19]. These results indicate that some amount of fertiliser DS could be lost towards the FS and cannot be recovered. Mass balance analysis of the $\mathrm{NH}_{4}{ }^{+}$and $\mathrm{SO}_{4}{ }^{2-}$ in the feed tank indicates that about $504 \mathrm{~g}$ of $\mathrm{NH}_{4}{ }^{+}$and 1,925 $\mathrm{g}$ of $\mathrm{SO}_{4}{ }^{2-}$ (total DS of 2,429 $\mathrm{g}$ ) are lost by reverse diffusion towards the feed, which translates to $3.7 \%$ and $5.3 \%$ (total DS loss of $4.9 \%$ ) of their initial mass in the fertiliser DS, respectively, during each cycle of batch operation. This also shows that, for every mole of $\mathrm{SO}_{4}{ }^{2-}$ that reverse diffuse through the $\mathrm{FO}$ membrane, about 1.4 moles of $\mathrm{NH}_{4}$ reverse diffuse instead of expected 2 moles of $\mathrm{NH}_{4}$ based on their equimolar molar ratios in the $\left(\mathrm{NH}_{4}\right) \mathrm{SO}_{4} \mathrm{DS}$ solution. To maintain ion balance on the DS side, ions such as $\mathrm{Na}^{+}$or $\mathrm{Cl}^{-}$may cross the $\mathrm{FO}$ membrane towards the $\mathrm{DS}$ as indicated by the presence of $\mathrm{Na}^{+}$or $\mathrm{Cl}^{-}$in the DS. This therefore likely enhances the feed solute flux through the membrane resulting in slightly lower rejection rates of $\mathrm{Na}^{+}(72 \%)$ or $\mathrm{Cl}^{-}(81 \%)$ compared to reported rejection of between $94 \%-99 \%$ [41, $\underline{42}]$.

The SAR values of the diluted DS in Table 2 increased to $42.0( \pm 5.5)$ compared to $24.5( \pm 3.4)$ in the initial feed water due to the high rejection of $\mathrm{Ca}^{2+}$ and $\mathrm{Mg}^{2+}$ ions compared to $\mathrm{Na}^{+}$ions by the FO membrane. The recommended SAR value is less than 6 although SAR values greater than 5 are considered as at the risk of adverse structural impacts associated with 
sodicity [26]. Hence, based on the SAR values from Table 2, it is clear that, the diluted fertiliser DS is not suitable for irrigation.

Table 2: Characteristics of the feed water and diluted DS before and after the FDFO experiments. The average feed rejection rates $(\mathrm{R})$ for each ion were determined based on the average concentrations of each ion in the initial and final DS. The standard deviation of all the six samples is provided in the brackets). ( $\left(\mathrm{FS}_{\mathrm{F}}\right.$ : final feed solution, $\mathrm{DS}_{\mathrm{F}}=$ final draw solution, $R$ : feed rejection rate, SRSF: specific reverse solute flux). The osmotic pressure of the two types of saline feed water presented in Table 1 was calculated using the ROSA software (Version 9.1, Filmtec DOW ${ }^{\mathrm{TM}}$ Chemicals, USA).

\begin{tabular}{lcccc}
\hline Parameters & $\mathbf{F S}_{\mathbf{F}}$ & $\mathbf{D S}_{\mathbf{F}}$ & $\mathbf{R}(\boldsymbol{\%})$ & $\begin{array}{c}\text { SRSF } \\
(\mathbf{m g} / \mathbf{L})\end{array}$ \\
\hline $\mathrm{pH}$ & $8.0( \pm 0.20)$ & $7.7( \pm 0.06)$ & & \\
$\mathrm{EC}(\mathrm{mS} / \mathrm{cm})$ & $7.5( \pm 0.8)$ & $13.49( \pm 1.5)$ & & \\
Turbidity $(\mathrm{NTU})$ & $1.9( \pm 0.2)$ & $0.25( \pm 0.05)$ & & \\
$\mathrm{NH}_{4}(\mathrm{mg} / \mathrm{L} \mathrm{N})$ & $113( \pm 14)$ & $1897( \pm 143)$ & & $105( \pm 76)$ \\
$\mathrm{Na}(\mathrm{mg} / \mathrm{L})$ & $1425( \pm 202)$ & $231( \pm 40)$ & $72 \%( \pm 3.5 \%)$ & \\
$\mathrm{K}(\mathrm{mg} / \mathrm{L})$ & $19( \pm 7)$ & $1.2( \pm 0.3)$ & $83 \%( \pm 3.6 \%)$ & \\
$\mathrm{Ca}(\mathrm{mg} / \mathrm{L})$ & $58( \pm 19)$ & $1.5( \pm 0.5)$ & $97 \%( \pm 1.0 \%)$ & \\
$\mathrm{Mg}(\mathrm{mg} / \mathrm{L})$ & $31( \pm 3)$ & $0.5( \pm 0.3)$ & $98 \%( \pm 1.3 \%)$ & \\
$\mathrm{Cl}(\mathrm{mg} / \mathrm{L})$ & $1897( \pm 595)$ & $185( \pm 8.7)$ & $81 \%( \pm 0.7 \%)$ & \\
$\mathrm{SO}{ }_{4}\left(\mathrm{mg} / \mathrm{L} \mathrm{SO}{ }_{4}{ }^{2-}\right)$ & $992( \pm 167)$ & $5288( \pm 233)$ & & $401( \pm 85)$ \\
$\mathrm{SAR}$ & 37.8 & $42.0( \pm 5.5)$ & & \\
TDS $(\mathbf{m g} / \mathbf{L})$ & $\mathbf{4 5 3 5}( \pm \mathbf{2 2 0})$ & $\mathbf{7 6 0 4}( \pm \mathbf{8 4 5})$ & & \\
Osmotic pressure & $\mathbf{2 . 8 5}( \pm \mathbf{0 . 1 4})$ & $\mathbf{3 . 7 0}( \pm \mathbf{0 . 4 1})$ & & \\
(bar) & & & & \\
\hline
\end{tabular}

\subsection{Operation of the nanofiltration process}

With a single $4040 \mathrm{NF}$ element in the module, the maximum recovery rate for the NF module was only $20-25 \%$ when operated at a constant transmembrane pressure of 25 bar. Hence, the NF process was operated in a batch mode where the NF concentrate was recycled back to the NF feed tank. In this way, the concentration of the NF feed tank containing fertiliser solution increased constantly with time. Variations of the water flux and the permeate EC has 
therefore been plotted as a function of the feed concentration or EC at the module inlet instead of operation time.

Figure 5 shows the variations of the performance parameters such as specific permeate water flux, NF permeate EC and NF rejection rate as a function of the cumulative EC of the diluted fertiliser DS or the NF feed. The initial NF feed EC was $13.49( \pm 1.5) \mathrm{mS} / \mathrm{cm}$ as per the composition presented in Table 2. The lowest desirable final diluted DS concentration from the FDFO process should have an osmotic pressure of $1.52 \mathrm{~atm}$, equal to the osmotic pressure of the initial saline feed water at the inlet. This equivalent concentration for the DS has been estimated to be $\sim 7,000 \mathrm{mg} / \mathrm{L}$ of SOA (EC of $11.9 \mathrm{mS} / \mathrm{cm}$ ). Since the maximum volume of the DS tank was 5,000 L and the feed water TDS also slightly increased with time during the operation, the minimum final diluted DS concentration was 7,604 $( \pm 845) \mathrm{mg} / \mathrm{L}$ with an osmotic pressure of $3.7( \pm 0.41)$ bar, which is higher than the desirable concentration. Hence, it must be understood here that the feed water for the NF post-treatment has an osmotic pressure twice as high as the saline feed water and will increase the energy requirement for the NF process post-treatment.

For each cycle, NF was operated until such time that the water flux was so low at 25 bar to be accurately measured by the permeate flow meter and this happened when the final diluted fertiliser DS or NF feed reached an EC of around $39-42 \mathrm{mS} / \mathrm{cm}$, translating to a total or overall NF feed recovery rate of around $65-70 \%$. The results in Figure 5(a) show that the water fluxes for the NF process did not vary significantly, even after six cycles of batch operations, indicating that the NF process performed quite consistently without having any membrane scaling and fouling. This is because the diluted fertiliser DS used as the NF feed is a high quality water, similar to RO treated water, except for the presence of SOA fertiliser solutes. The use of high quality FO treated feed water with very low or no fouling potential 
could be one of the major advantages since NF is the most energy intensive process in the FDFO-NF desalination system. Any organics and colloids or scaling ions such as $\mathrm{Ca}^{2+}$ and $\mathrm{Mg}^{2+}$ present in the saline feed water are expected to be almost fully removed during the FO process, as indicated by the water characteristics of the final diluted DS in Table 2. It is worth noting here that, during the entire NF operation, the membrane was never cleaned, indicating that cleaning costs of the NF process will also be significantly lower when used as posttreatment process in FDFO desalination.

Figure 5(b) shows the variations of the permeate EC and NF rejection rate with the bulk cumulative EC of the NF feed water. The permeate EC is important as it is directly related to the quality of the product water for fertigation. The permeate EC increases with the increase in the bulk EC of the diluted fertiliser DS in the NF feed tank since the NF was operated in a batch mode, however, the NF rejection rate did not change significantly even at higher NF feed concentration with rejections rates above $96 \%$. There was no significant difference or trend observed in the permeate EC between each NF cycle in Figure 5(b), which is also supported by the similar fertiliser rejection rate of the NF membrane after several cycles of operations. A typical composition of the NF permeate along with the STD are presented in Table 3 and this in fact represents a typical quality of the fertigation water produced from the FDFO-NF desalination system. The average EC of the final product water from the FDFONF system was about $810( \pm 30) \mu \mathrm{S} / \mathrm{cm}$, which is suitable for irrigation purpose. Table 3 provides the detail composition of the final product water from the FDFO-NF desalination system. The average $\mathrm{NH}_{4}-\mathrm{N}$ concentrations were observed to be $75( \pm 15) \mathrm{mg} / \mathrm{L}$, which is lower than the acceptable upper limit of $200 \mathrm{mg} / \mathrm{L}[\underline{19}, \underline{26}]$. The average $\mathrm{SO}_{4}{ }^{2-}$ concentration observed was $165( \pm 44) \mathrm{mg} / \mathrm{L}$, which is also and deemed suitable for irrigation. $\mathrm{SO}_{4}{ }^{2-}$ has no reported adverse impact on the soil or plants except for its contribution towards the salinity 
content, although too high concentration could reduce nitrate, phosphorous and molybdenum absorptivity of the plants [43].

In fact, all other ion concentrations were much lower than the maximum allowable limit for fertigation. Although a higher level of the essential ions such as $\mathrm{Ca}^{2+}$ and $\mathrm{Mg}^{2+}$ would be preferred, their concentrations dipped below $1.0 \mathrm{~g} / \mathrm{L}$ (because of the high rejection of these divalent cations by the NF membrane). The low $\mathrm{Na}^{+}$concentrations in the final product water (average SAR value 4.0( \pm 0.57$)$ ) was still lower and within the acceptable values of less than 6 for irrigation [26]. Given the low permeate EC (Table 3) with the NE90 module it appears that even NF membranes as with lower rejection (such as NE70) could also be potentially used as post-treatment in the process, thereby reducing the energy costs as NF70 is expected to have much higher water flux than NE90 given its slightly larger pore size and higher water permeability.

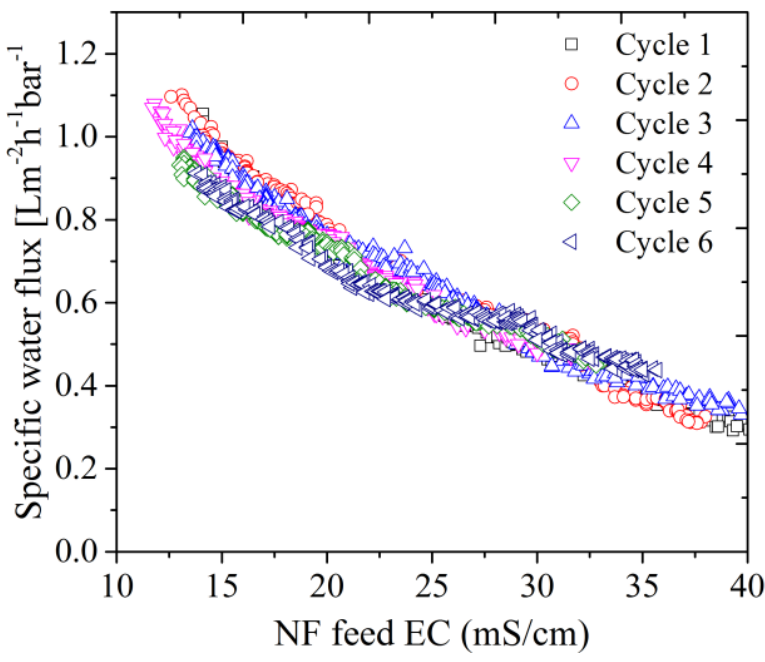

(a)

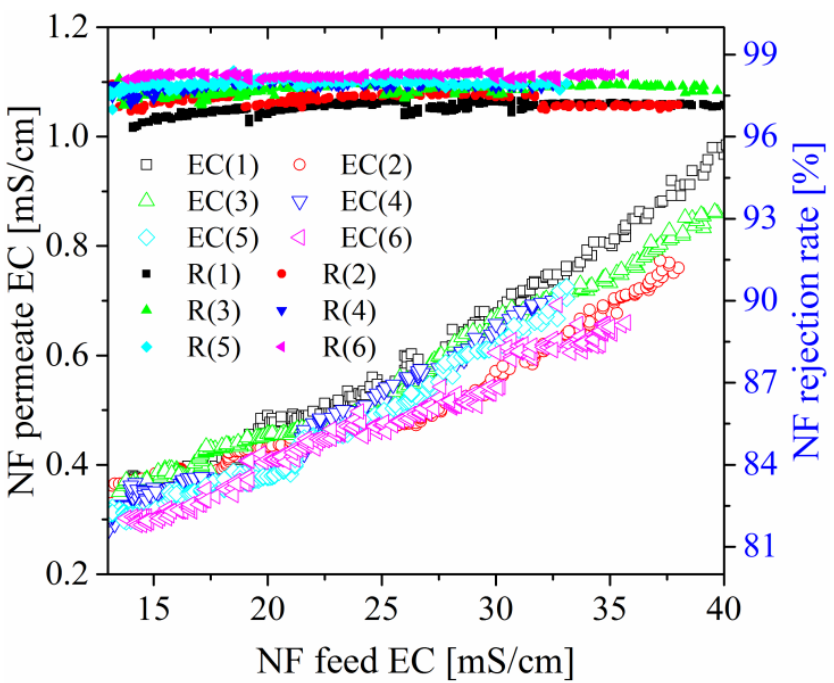

(b)

Figure 5: Performance of the NF process as post-treatment using the diluted fertiliser DS from the FDFO desalination process as NF feed water. Variations of the (a) specific NF permeate flux and (b) NF permeate electrical conductivity and NF rejection rate with the 
cumulative increase in the NF feed concentration (diluted fertiliser) during the batch NF operation process.

Table 3: Characteristics of NF permeate using diluted fertiliser DS as the NF feed. The standard deviation of all the six samples is provided in the brackets.

\begin{tabular}{lcccc}
\hline \multicolumn{1}{c}{ Parameters } & $\begin{array}{c}\text { Initial NF } \\
\text { Feed }\left(\mathbf{D S}_{\mathbf{F}}\right)\end{array}$ & $\mathbf{P}(\mathbf{a v e})$ & $\begin{array}{c}\mathbf{N F} \\
\text { Con. }\end{array}$ & $\mathbf{R}_{\mathbf{N F}}(\%)$ \\
\hline $\mathrm{pH}$ & $7.7( \pm 0.06)$ & $8.15( \pm 0.15)$ & $8.1( \pm 0.17)$ & \\
$\mathrm{EC}(\mathrm{mS} / \mathrm{cm})$ & $13.49( \pm 1.5)$ & $0.81( \pm 0.03)$ & $42.9( \pm 3.23)$ & $94.0 \%( \pm 0.2 \%)$ \\
Turbidity (NTU) & $0.25( \pm 0.05)$ & $0.1( \pm 0.1)$ & $0.8( \pm 0.1)$ & \\
Ammonia (mg/L N) & $1897( \pm 143)$ & $75( \pm 15)$ & $6,140( \pm 562)$ & $96.0 \%( \pm 0.8 \%)$ \\
Sodium (mg/L) & $231( \pm 40)$ & $10( \pm 1.1)$ & $752( \pm 63)$ & $95.7 \%( \pm 3.5 \%)$ \\
Potassium (mg/L) & $1.2( \pm 0.3)$ & $0.2( \pm 0.1)$ & $8.5( \pm 0.9)$ & $83.3 \%( \pm 6.9 \%)$ \\
Calcium (mg/L) & $1.5( \pm 0.5)$ & $0.15( \pm 0.05)$ & $5.0( \pm 1.4)$ & $90.0 \%( \pm 3.0 \%)$ \\
Magnesium (mg/L) & $0.5( \pm 0.3)$ & $0.2( \pm 0.07)$ & $2.0( \pm 0.9)$ & $60.0 \%( \pm 8.4 \%)$ \\
Chloride $(\mathrm{mg} / \mathrm{L})$ & $185( \pm 8.7)$ & $15( \pm 2.1)$ & $540.0( \pm 52.0)$ & $91.9 \%( \pm 1.0 \%)$ \\
$\mathrm{SO}_{4}{ }^{2-}$ & $5288( \pm 233)$ & $165( \pm 44)$ & $17250( \pm 2019)$ & $96.9 \%( \pm 0.8 \%)$ \\
$\mathrm{TDS}$ & $7604( \pm 845)$ & $\sim 266( \pm 10.5)$ & $\sim 24700( \pm 8000)$ & $96.5 \%( \pm 1.5 \%)$ \\
$\mathrm{SAR}$ & $42.0( \pm 5.5)$ & $4.0( \pm 0.57)$ & $72.4( \pm 6.2)$ & \\
\hline
\end{tabular}

\subsection{Implications of solute fluxes in a closed loop FDFO-NF system}

Each long-term cycle for the FDFO desalination was operated at a total overall feed recovery rate of about $49 \%(4,800 \mathrm{~L}$ of water permeated from the FS towards the 5,000 L DS tank with the final concentrate volume of 5,000 L). For this overall feed recovery rate, the FDFO concentrate resulted in a $\mathrm{NH}_{4}{ }^{+}$of $105( \pm 76) \mathrm{mg} / \mathrm{L}$ and $\mathrm{SO}_{4}{ }^{2-}$ of $401( \pm 85) \mathrm{mg} / \mathrm{L}$, which is expected to increase at higher recovery rates. Mass balance analysis of the feed and the reverse draw solutes indicate that, the concentration of the lost draw solutes in the FO feed brine in a full-scale continuous FDFO operation would increase exponentially as $[\overline{S R S F} \mathrm{x}$ $\overline{R R} /(1-\overline{R R})]$ with the feed recovery rates $(R R)$ as precented in Figure 6(a). This is because, as feed recovery rate increases, brine flow rate decreases but contain the same mass of the draw solutes that reverse diffuse through the membrane and this mass depends on the permeate 
flow rate and the SRSF. Therefore, a higher feed recovery rate in the FDFO process would likely mean higher concentrations of $\mathrm{NH}_{4}{ }^{+}$and $\mathrm{SO}_{4}{ }^{2-}$ draw solutes in the feed concentrate/brine, which could be a cause of concern not only from the economic point of view but also for the environmental discharge of the concentrate containing $\mathrm{NH}_{4}-\mathrm{N}$ nutrient.

According to NSW EPA regulation, the allowable limit for the environmental discharge of TN from a sewage treatment plant is $10 \mathrm{mg} / \mathrm{L} \mathrm{[44]}$ and hence, the FDFO concentrate/brine in this study (113 mg/L at $49 \%$ feed recovery rate) does not meet the water quality standard for environmental discharge to the creek. The presence of nitrogen in the feed concentrate will therefore be one of the major issues for concentrate management in the FDFO desalination process. The permissible environmental discharge limit for $\mathrm{SO}_{4}{ }^{2-}$ at the coal mine site is 232 $\mathrm{mg} / \mathrm{L}[45]$ and hence $\mathrm{SO}_{4}{ }^{2-}$ too does not meet the environmental discharge standard. These results indicate that the CTA FO membrane used in this study is not suitable for the FDFO desalination and hence a better performing and high rejecting FO membrane may be essential for the actual FDFO desalination plants.

It is also important to understand the characteristics of the NF concentrate which is to be recycled back to the FDFO process for further reuse as the concentrated DS. The diluted DS (Table 2) contains other feed elements such as $\mathrm{Na}^{+}(231 \pm 40 \mathrm{mg} / \mathrm{L})$ and $\mathrm{Cl}^{-}(185 \pm 8.7 \mathrm{mg} / \mathrm{L})$ and based on these results the FO membrane rejection rates were $95.7 \%( \pm 3.5 \%)$ for $\mathrm{Na}$ and $92 \%( \pm 1 \%)$ for $\mathrm{Cl}$ (average of $94 \%$ for $\mathrm{Na}$ and $\mathrm{Cl}$ added). Although the feed $\mathrm{NaCl}$ concentrations in the diluted DS (Table 2 and 3) does not appear significant however, as these feed solutes are rejected by the NF membrane, their concentration increases in the NF concentrate to $752( \pm 63) \mathrm{mg} / \mathrm{L}$ for $\mathrm{Na}^{+}$and $540( \pm 52) \mathrm{mg} / \mathrm{L}$ for $\mathrm{Cl}^{-}$in the batch process. As this $\mathrm{NF}$ concentrate containing $\mathrm{Na}^{+} / \mathrm{Cl}^{-}$concentration is recycled back and reused in the FDFO 
process infinite times, this could eventually build up $\mathrm{Na}^{+}$or $\mathrm{Cl}^{-}$concentrations in the concentrated fertiliser DS.

Figure 6(b) presents the expected increase in the feed $\mathrm{Na}$ and $\mathrm{Cl}$ concentrations with time in the concentrated DS under a full-scale continuous and closed loop FDFO-NF operation based on rejection rates of the FO membrane (Table 2) and NF membrane (Table 3). Simulation was performed assuming a plant capacity of 2,200 $\mathrm{m}^{3} \mathrm{day}^{-1}$, initial SOA DS concentrations of $60 \mathrm{~g} / \mathrm{L}, \mathrm{SRSF}$ of $\mathrm{Na}+\mathrm{Cl}=0.46 \mathrm{~g} / \mathrm{L}$ based on other study [46] and compared under three different combined scenarios of $\mathrm{FO}$ and $\mathrm{NF}$ membrane $\mathrm{Na}$ and $\mathrm{Cl}$ rejection rates. Based on a simple mass balance calculations within the closed loop FDFO-NF system, $\mathrm{Na}$ and $\mathrm{Cl}$ accumulation can be calculated by the following relationship:

$$
\text { Accumulation Rate (in } \mathrm{g} / \mathrm{s})=\frac{C_{F, \text { in }}\left(1-R_{F O}\right)\left(1+R_{N F}-R R_{N F}\right) Q_{p}}{2-R R_{N F}}
$$

where $C_{F, i n}$ is the feed salt concentration $(\mathrm{Na}$ and $\mathrm{Cl}), R_{F O}$ is the feed salt rejection by $\mathrm{FO}$ membrane, $R_{N F}$ is the feed salt rejection (of the diluted DS) by NF membrane, $R R_{N F}$ is the feed (diluted DS) recovery rate of the NF process, and $Q_{p}$ is the plant capacity.

Based on the above mass balance relationship and for the above assumed plant capacity, the feed salt $\left(\mathrm{Na}\right.$ and $\mathrm{Cl}$ ) would accumulate at $16.35 \mathrm{gs}^{-1}$. It is clear from Figure 6(b) that after about 20 hours of continuous FDFO-NF operations, the $\mathrm{Na}$ and $\mathrm{Cl}$ concentration would reach about $68 \mathrm{~g} / \mathrm{L}$, which is more than $50 \%$ of the total solutes present in the concentrated DS. This will consequently increase the $\mathrm{Na} / \mathrm{Cl}$ concentrations in the $\mathrm{NF}$ permeate $(4.08 \mathrm{~g} / \mathrm{L}$ $\mathrm{Na}+\mathrm{Cl}$ at $94 \% \mathrm{NF}$ rejection rate) undermining the irrigation water quality. These simulations took into consideration the $\mathrm{NaCl}$ bleeding from the closed system through $\mathrm{NF}$ permeate and the re-reverse diffusion of $\mathrm{NaCl}$ through the $\mathrm{FO}$ membrane towards the feed water. Hence, 
the accumulation of feed salt within the closed FDFO-NF system could be one of the significant challenges of recycling and reusing the fertiliser DS if a similar CTA FO membrane is used for full-scale FDFO-NF application. This problem, however, could be minimised by using high salt rejecting FO membranes such as polyamide based thin film composite FO membranes for the FDFO process to limit the passage or permeation of $\mathrm{Na}^{+}$ and $\mathrm{Cl}^{-}$to the diluted DS.

Figure 6(b) also however shows that, using thin film composite TFC FO membrane (HTI) with comparable $\mathrm{NaCl}$ rejection $(91.5 \%)$ but with lower SRSF $(0.279 \mathrm{~g} / \mathrm{L})$ [41] can slow down the $\mathrm{NaCl}$ salt build-up. The alternate approach is to use lower rejection NF membranes as presented for $\mathrm{NF}$ rejection $(80 \%)$ that can enhance $\mathrm{NaCl}$ bleeding from the closed system thereby slowing down the slat build-up. However, NF permeate must also meet the fertigation standard in terms of salinity and the fertiliser concentration when such NF membranes are used. Theoretically the salt build-up could be avoided only if the bleeding of $\mathrm{NaCl}$ from the system through $\mathrm{NF}$ permeation and re-reverse diffusion through the $\mathrm{FO}$ membrane is equal to permeation from the FO process. These findings complements the study by Benavides et al. [47] that the reverse flux selectivity or the ratio of the forward water flux to the reverse draw solute flux, is a key parameter in the design of FO systems.
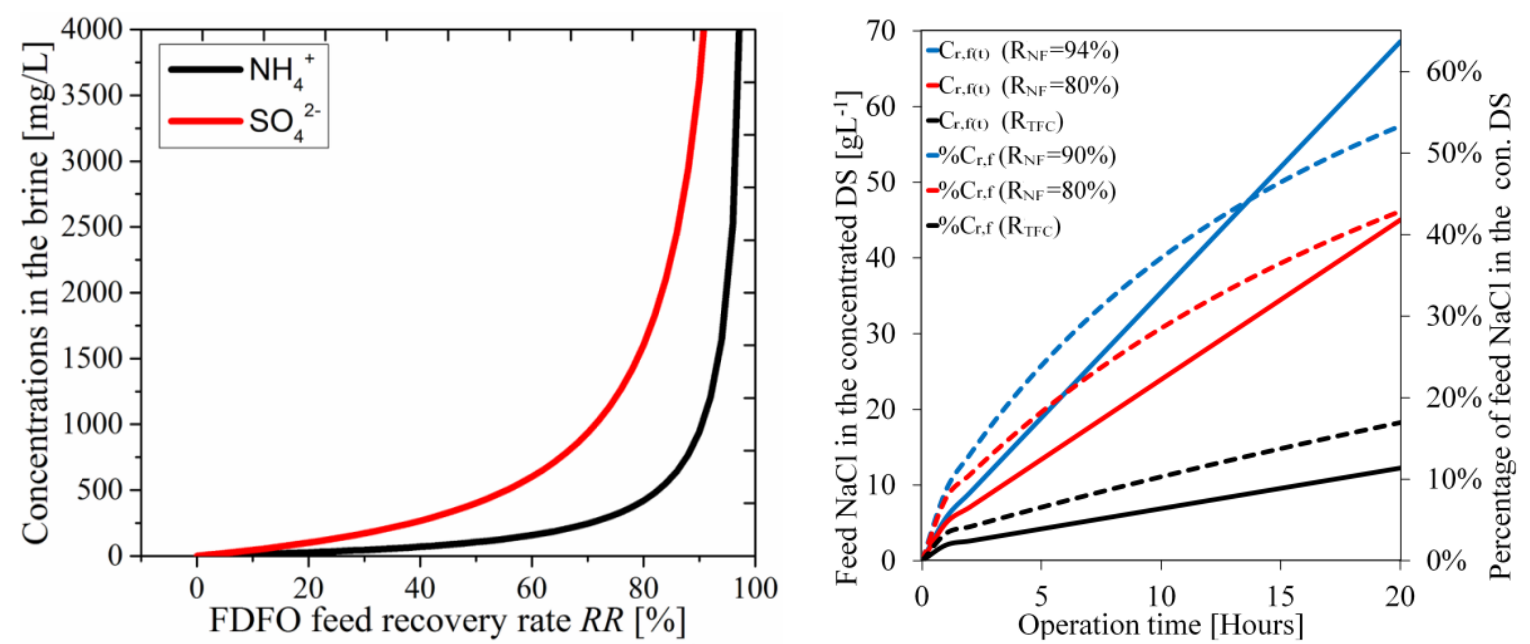
Figure 6: Implications of solutes transfer through the FO and NF membranes assessed based on the (a) expected variations of the draw solute concentrations in the FDFO feed concentrate/brine at different FDFO feed recovery rates where the $\mathrm{NH}_{4}{ }^{+}$and $\mathrm{SO}_{4}{ }^{2-}$ concentrations in the brine was calculated using the relationship $[\overline{S R S F} \times \overline{R R} /(1-\overline{R R})](\mathrm{RR}$ is the feed recovery rate) and (b) expected variations of the feed solute $(\mathrm{NaCl})$ concentrations in the concentrated SOA DS under different FO and NF rejection rates. For simulation, $\mathrm{NaCl}$ feed rejection of CTA FO membrane at $\mathrm{R}_{\mathrm{FO}}=87.6 \%$, SRSF of $\mathrm{NaCl}$ was assumed at $0.46 \mathrm{~g} / \mathrm{L}$ [46], for $\mathrm{R}_{\mathrm{FO}}=90 \%$, SRSF was assumed at $0.327 \mathrm{~g} / \mathrm{L}$ [41] and the NF feed recovery rate was assumed about $84 \%$.

\section{Conclusions}

The following conclusions have been drawn from this particular study:

- The feed water quality could affect membrane fouling and the performance of the FDFO process, however, this study observed that hydraulic cleaning was adequate to almost fully recover the water flux under the conditions tested.

- Although the NF process could still consume energy, it is expected to perform efficiently without being significantly affected by membrane fouling or scaling issues as it receives an excellent feed water quality treated by the FDFO process.

- Using NF membrane with lower rejection and higher permeability could potentially save NF energy consumption while still meeting the water quality for fertigation.

- The high SRSF of $\mathrm{NH}_{4}{ }^{+}$and $\mathrm{SO}_{4}{ }^{2-}$ using CTA-FO membrane have failed to meet the standard for feed brine discharge which further increased at higher feed recovery rates, making brine management one of the biggest challenges of the FDFO system.

- Low feed rejection of the CTA FO membrane also could result in the build-up of feed salts such as $\mathrm{Na}^{+}$and $\mathrm{Cl}^{-}$in the DS during repetitive recycling and reuse, eventually 
affecting the final water quality unless adequate bleeding from the closed FDFO-NF system occurs through NF permeate and also through re-reverse diffusion from the recycled and reused DS.

- This study demonstrates the significance for the need to have FO membranes with higher membrane reverse flux selectivity (e.g. polyamide based thin film composite membranes) for the FDFO-NF desalination technology to become a commercial reality.

Although this study demonstrated that the integrated FDFO-NF desalination system is technically feasible for fertigation purpose, a detailed economic analysis is important to fully understand its comparative advantages with existing desalination technologies such as the RO process. As part of this same project, an economic analysis and the full life cycle analysis of the integrated FDFO-NF desalination system is currently being conducted and will be submitted in a separate manuscript.

\section{Acknowledgements}

The authors acknowledge the financial support of the National Centre of Excellence in Desalination Australia which is funded by the Australian Government through the National Urban Water and Desalination Plan. The authors also acknowledge the partial support received for this study from ARC discovery grant (DP140100835), ARC Future Fellowship (FT140101208) and University of Technology, Sydney chancellor's postdoctoral research fellowship. Funding for this research was also provided by the Water Desalination and Reuse Center (WDRC) at the King Abdullah University of Science and Technology (KAUST), Saudi Arabia and by Industrial Facilities \& Infrastructure Research Program (14IFIPB087385-01) by Ministry of Land, Infrastructure and Transport of Korean Government. 


\section{References}

1. F.R. Rijsberman, Water scarcity: Fact or fiction?, Agric. Water Manag., 80 (2006) 522.

2. J.E. Kharraz, A. El-Sadek, N. Ghaffour, and E. Mino, Water scarcity and drought in WANA countries, Procedia Engineering, 33 (2012) 14-29.

3. C.J. Vörösmarty, P. Green, J. Salisbury, and R.B. Lammers, Global Water Resources: Vulnerability from Climate Change and Population Growth, Sci., 289 (2000) 284-288.

4. I. Haddeland, J. Heinke, H. Biemans, S. Eisner, M. Flörke, N. Hanasaki, M. Konzmann, F. Ludwig, Y. Masaki, J. Schewe, T. Stacke, Z.D. Tessler, Y. Wada, and D. Wisser, Global water resources affected by human interventions and climate change, Proc. Natl. Acad. Sci., 111 (2014) 3251-3256.

5. E. Lopez-Gunn and M. Ramón Llamas, Re-thinking water scarcity: Can science and technology solve the global water crisis?, Nat. Resour. Forum, 32 (2008) 228-238.

6. UN, Role of desalination in addressing water scarcity / Economic and Social Commission for Western Asia. ESCWA water development report ; 3., ed. E. United Nations and A. Social Commission for WesternUnited Nations. New York :: 2009.

7. N. Ghaffour, T.M. Missimer, and G.L. Amy, Technical review and evaluation of the economics of water desalination: Current and future challenges for better water supply sustainability, Desalination, 309 (2013) 197-207.

8. J.M. Beltrán and S. Koo-Oshima. Water desalination for agricultural applications in: Food and Agriculture Organization of the Nations. in Proceedings of the FAO Expert Consultation on Water Desalination for Agricultural Applications. 2006. FAO, Rome, Italy.

9. D.L. Shaffer, N. Yin Yip, J. Gilron, and M. Elimelech, Seawater desalination for agriculture by integrated forward and reverse osmosis: improved product water quality for potentially less energy, J. Membr. Sci., 415-416 (2012) 1-8.

10. Q. Ge, M. Ling, and T.-S. Chung, Draw solutions for forward osmosis processes: Developments, challenges, and prospects for the future, J. Membr. Sci., 442 (2013) 225-237.

11. J.-J. Qin, W.C.L. Lay, and K.A. Kekre, Recent developments and future challenges of forward osmosis for desalination: a review, Desalination Water Treat., 39 (2012) 123136.

12. S. Zhao, L. Zou, C.Y. Tang, and D. Mulcahy, Recent developments in forward osmosis: Opportunities and challenges, J. Membr. Sci., 396 (2012) 1-21.

13. T.Y. Cath, J.E. drewes, and C.D. Lundin, A novel hybrid forward osmosis process for drinking water augmentation using impaired water and saline water sources, 2009, WERC and Water Research foundation.

14. L. Chekli, S. Phuntsho, H.K. Shon, S. Vigneswaran, J. Kandasamy, and A. Chanan, A review of draw solutes in forward osmosis process and their use in modern applications, Desalination Water Treat., 43 (2012) 167-184.

15. S. Phuntsho, H.K. Shon, S. Hong, S. Lee, and S. Vigneswaran, A novel low energy fertilizer driven forward osmosis desalination for direct fertigation: evaluating the performance of fertilizer draw solutions, J. Membr. Sci., 375 (2011) 172-181.

16. S. Phuntsho, H.K. Shon, S. Hong, S. Lee, S. Vigneswaran, and J. Kandasamy, Fertiliser drawn forward osmosis desalination: the concept, performance and limitations for fertigation, Rev. Environ. Sci. Bio/Technol., 11 (2012) 147-168.

17. C.D. Moody and J.O. Kessler, Forward osmosis extractors, Desalination, 18 (1976) 283-295. 
18. S. Phuntsho, S. Hong, M. Elimelech, and H.K. Shon, Osmotic equilibrium in the forward osmosis process: Modelling, experiments and implications for process performance, J. Membr. Sci., 453 (2014) 240-252.

19. S. Phuntsho, H.K. Shon, T. Majeed, I. El Saliby, S. Vigneswaran, J. Kandasamy, S. Hong, and S. Lee, Blended fertilizers as draw solutions for fertilizer-drawn forward osmosis desalination, Environ. Sci. Technol., 46 (2012) 4567-4575.

20. S. Phuntsho, S. Hong, M. Elimelech, and H.K. Shon, Forward osmosis desalination of brackish groundwater: Meeting water quality requirements for fertigation by integrating nanofiltration, J. Membr. Sci., 436 (2013) 1-15.

21. S. Sahebi, S. Phuntsho, J.E. Kim, S.K. Hong, and H.K. Shon, Pressure assisted fertiliser drawn osmosis process to enhance final dilution of the fertiliser draw solution beyond osmotic equilibrium, J. Membr. Sci., 481 (2015) 63-72.

22. G. Blandin, A.R.D. Verliefde, C.Y. Tang, A.E. Childress, and P. Le-Clech, Validation of assisted forward osmosis (AFO) process: Impact of hydraulic pressure, J. Membr. Sci., 447 (2013) 1-11.

23. J.E. Kim, S. Phuntsho, F. Lotfi, and H.K. Shon, Investigation of pilot-scale 8040 FO membrane module under different operating conditions for brackish water desalination, Desalination Water Treat., doi: 10.1080/19443994.2014.931528 (2014).

24. Y.C. Kim and S.-J. Park, Experimental Study of a 4040 Spiral-Wound ForwardOsmosis Membrane Module, Environ. Sci. Technol., 45 (2011) 7737-7745.

25. APHA, Standard methods for the examination of water and wastewaterAmerican Public Health Association: 2005.

26. A. Phocaides, Handbook on pressurized irrigation techniques, 2007, Food and Agriculture Organization, UN: Rome.

27. S. Phuntsho, S. Sahebi, T. Majeed, F. Lotfi, J.E. Kim, and H.K. Shon, Assessing the major factors affecting the performances of forward osmosis and its implications on the desalination process, Chem. Eng. J., 231 (2013) 484-496.

28. J.E. Kim, S. Phuntsho, and H.K. Shon, Pilot-scale nanofiltration system as posttreatment for fertilizer-drawn forward osmosis desalination for direct fertigation, Desalination Water Treat., 51 (2013) 6265-6273.

29. BOM, Climate data online. Bureau of Metreology, Australian Government., 2015, Accessed: 02/01/2015];

30. ANZ-ECC and ARMCANZ, National water quality management strategy: An introduction to Australian and New Zealand Guidelines for Fresh and Marine Water Quality - 4A, 2000, Australian and New Zealand Environment and Conservation Council (ANZ-ECC) and Agriculture and Resource Management Council of Australia and New Zealand (ARMCANZ).

31. E.M. Garcia-Castello, J.R. McCutcheon, and M. Elimelech, Performance evaluation of sucrose concentration using forward osmosis, J. Membr. Sci., 338 (2009) 61-66.

32. W.C.L. Lay, J. Zhang, C. Tang, R. Wang, Y. Liu, and A.G. Fane, Factors affecting flux performance of forward osmosis systems, J. Membr. Sci., 394-395 (2012) 151-168.

33. C. DOW, Product Information for DOW ${ }^{\mathrm{TM}}$ Filmtec BW30-440i, 2014, DOW ${ }^{\mathrm{TM}}$ Filmtec Membranes, DOW Chemicals.

34. I. Papadopoulos, Fertigation-chemigation in protected agriculture, Cahiers options Mediterraneennes, 31 (1999) 275-291.

35. R. Munns, Comparative physiology of salt and water stress, Plant, Cell Environ., 25 (2002) 239-250.

36. Y. Wang, R. Ou, H. Wang, and T. Xu, Graphene oxide modified graphitic carbon nitride as a modifier for thin film composite forward osmosis membrane, J. Membr. Sci., 475 (2015) 281-289. 
37. J. Wei, C. Qiu, C.Y. Tang, R. Wang, and A.G. Fane, Synthesis and characterization of flat-sheet thin film composite forward osmosis membranes, J. Membr. Sci., 372 (2011) 292-302.

38. K.Y. Wang, R.C. Ong, and T.-S. Chung, Double-Skinned Forward Osmosis Membranes for Reducing Internal Concentration Polarization within the Porous Sublayer, Industrial \& Engineering Chemistry Research, 49 (2010) 4824-4831.

39. N.T. Hancock, W.A. Phillip, M. Elimelech, and T.Y. Cath, Bidirectional Permeation of Electrolytes in Osmotically Driven Membrane Processes, Environ. Sci. Technol., 45 (2011) 10642-10651.

40. W.A. Phillip, J.S. Yong, and M. Elimelech, Reverse Draw Solute Permeation in Forward Osmosis: Modeling and Experiments, Environ. Sci. Technol., 44 (2010) 51705176.

41. J. Ren and J.R. McCutcheon, A new commercial thin film composite membrane for forward osmosis, Desalination, 343 (2014) 187-193.

42. J.R. McCutcheon, R.L. McGinnis, and M. Elimelech, Desalination by ammonia-carbon dioxide forward osmosis: Influence of draw and feed solution concentrations on process performance, J. Membr. Sci., 278 (2006) 114-123.

43. R.S. Ayers and D.W. Westcot, Water quality for agriculture, 1985, Food and Agriculture Organization, United Nations: Rome.

44. NSW-EPA, Protection of the Environment Operations (General) Regulation 2009. Version in 2009 No 2112009: New South Wales State, Australia.

45. V. Howat, Annual environmental management report 2013: Newstan Colliery, 2013.

46. Q. She, X. Jin, Q. Li, and C.Y. Tang, Relating reverse and forward solute diffusion to membrane fouling in osmotically driven membrane processes, Water Res., 46 (2012) 2478-2486.

47. S. Benavides, A.S. Oloriz, and W.A. Phillip, Forward Osmosis Processes in the Limit of Osmotic Equilibrium, Ind. Eng. Chem. Res., (2014). 